\title{
FATORES SOCIOAMBIENTAIS NA EPIDEMIOLOGIA DA ESQUISTOSSOMOSE NO OESTE DA BAHIA, BRASIL
}

\author{
DAYANE OTERO RODRIGUES, \\ LARISSA HELLEN DOS SANTOS PEREIRA.
}

\begin{abstract}
RESUMO - A Região Nordeste do Brasil é uma área de grande prevalência da esquistossomose, com destaque ao estado da Bahia, que apresenta grande parte do seu território como área endêmica da doença. A esquistossomose é um grave problema de saúde pública, já que a patogênese da doença pode levar o paciente ao óbito e dentre os fatores ambientais relacionados à sua transmissão destaca-se a falta de saneamento básico, uma vez que os ovos do parasita são eliminados nas fezes dos humanos podendo contaminar os mananciais aquáticos. O município de Barreiras, situado no Oeste da Bahia, é carente em condições básicas de saúde, principalmente nas áreas rurais, aumentando as chances de contaminação pelo helminto. Objetivos: Analisar a relação entre os fatores socioambientais e casos de esquistossomose em moradores do município de Barreiras, Oeste da Bahia. Metodologia: Foram coletados dados dos fatores de risco socioambientais e clínicos de 98 fichas de notificação obrigatória da Vigilância Epidemiológica de Barreiras de casos confirmados de esquistossomose dos anos de 2015 e 2018. Os dados foram analisados baseando-se nos testes qui-quadrado e exato de Fisher para verificar a associação entre as variáveis, sendo que o estudo se iniciou após aprovação pelo Comitê de Ética em Pesquisa da Universidade Federal do Oeste da Bahia. Resultados e Conclusão: A prevalência de esquistossomose em Barreiras é baixa em relação a outras regiões do estado. A maioria dos casos de infectados no município foi de moradores da zona rural, sendo que encontramos associação entre as variáveis forma clínica e idade dos infectados. Os fatores ambientais como a ausência de condições sanitárias adequadas com possível contaminação ambiental do município com os ovos do parasita e a presença de rios, córregos e represas na região com a presença do caramujo do gênero Biomphalaria favorecem a contaminação dos moradores principalmente da zona rural, mas também da urbana, em bairros sem infraestrutura e saneamento básico.
\end{abstract}

PALAVRAS-CHAVE - Schistosoma mansoni; Fatores socioambientais; Saneamento básico; Oeste da Bahia.

\section{INTRODUÇÃO}

A esquistossomose é uma doença causada por parasitas intestinais que em sua forma adulta colonizam os vasos sanguíneos do sistema porta num processo inflamatório crônico [1]. É uma doença provocada pelo Schistosoma mansoni e disseminada por contato com água contaminada por cercárias que se proliferam dentro dos caramujos do gênero Biomphalaria [2], sendo que B. glabrata destaca-se como principal agente intermediário de transmissão da esquistossomose no Brasil. A distribuição geográfica do Biomphalaria está essencialmente relacionada à disseminação dos focos, e a Bahia é o segundo estado com maior número de espécies do gênero [3].

A doença é endêmica nos continentes americano, asiático e africano, e sua transmissão no Brasil é frequente nos estados do Nordeste, além de Minas Gerais. No Nordeste destaca-se a região entre a Bahia e Pernambuco [4].
$\mathrm{O}$ estado da Bahia apresenta grande parte de seus municípios como áreas endêmicas para esquistossomose. Do total de 417 municípios da Bahia, 128 são endêmicos, 123 focais e 166 sem registros para transmissão da doença [5]. O município de Barreiras, situado no Oeste da Bahia, é um município carente, principalmente nas áreas rurais, de condições básicas de saúde, dentre elas a falta de infraestrutura e saneamento básico, aumentando as chances de contaminação pelo Schistosoma mansoni. Os estudos sobre a esquistossomose no município ainda são escassos, evidenciando a importância de novas pesquisas sobre tal tema na região. Ainda mais considerando-se que a doença é um grave problema de saúde pública, já que a patogênese da doença pode levar o paciente ao óbito se não tratada de forma adequada [6].

No município de Barreiras, os casos de portadores da esquistossomose são notificados pela Vigilância Epidemiológica de Barreiras (VIEP) e pelo Centro de Controle de 
Zoonoses de Barreiras (CCZ), ambos funcionando como uma Unidade de Vigilância em Saúde, com prestação de serviços de vigilância em saúde para a população do município.

Neste contexto, os fatores socioambientais como condições precárias e deficientes de saneamento básico, falta de orientação em educação e saúde e de políticas públicas preventivas adequadas são determinantes para a manutenção da doença na região. Sendo assim, no intuito de contribuir com a formação de subsídios à gestão pública para o planejamento mais eficaz das ações de controle e prevenção da doença na região, objetivou-se descrever a relação entre os fatores socioambientais e casos de esquistossomose em moradores do município de Barreiras, Oeste da Bahia, Brasil.

\section{METODOLOGIA}

\section{Desenho, área do estudo, população e amostra.}

Foi realizado um estudo epidemiológico transversal, retrospectivo, descritivo de 98 casos de esquistossomose da população barreirense, ocorridos no período de 2015 a 2018, detectados pela VIEP. Os fatores socioambientais e clínicos e características demográficas dos pacientes foram coletados da ficha de notificação obrigatória preenchida pela VIEP de Barreiras.

A pesquisa foi realizada no município de Barreiras, situado no extremo oeste baiano. O município apresenta uma área territorial de 7.861,762 km2 e concentra uma população de aproximadamente 153.831 [7]. O município de Barreiras é cortado pelo Rio Grande, principal afluente à margem esquerda do Rio São Francisco, e apresenta como principais rios, o Rio de Ondas, o Rio Branco e o Rio de Janeiro [8].

A região é conhecida e caracterizada por duas estações: uma seca e outra chuvosa, classificado assim como clima tropical estacional, onde apresenta um período chuvoso com duração de outubro a março e um período seco com duração de abril a setembro. A precipitação média anual é de 1.500 $\mathrm{mm}$, as temperaturas são geralmente amenas ao longo do ano, entre $22^{\circ} \mathrm{C}$ e $27^{\circ} \mathrm{C}$ em média [9] e a luminosidade em torno de 3.000 horas por ano [10].

Instrumento de coleta de dados.

Os dados secundários dos participantes da pesquisa foram resgatados da ficha de notificação obrigatória, observandose os seguintes fatores socioambientais, clínicos e características demográficas: presença de saneamento básico e de infraestrutura, como escoamento de água no bairro de moradia; presença de acúmulo de água nas ruas; presença de coleção hídrica próxima à moradia; uso de águas de rios, córregos ou represas para banho, recreação ou uso doméstico; bairro de residência; município provável de infecção; bairro provável de infecção; forma clínica da doença e idade.

O trabalho se iniciou somente após a aprovação pelo Comitê de Ética em Pesquisa da Universidade Federal do Oeste da Bahia, respeitando os padrões éticos preconizados pela Resolução 466/2012.

Análise dos dados.

Foi realizada uma análise descritiva das informações obtidas dos prontuários. Calculou-se a prevalência dos casos de esquistossomose em cada ano e os dados foram tabulados com auxílio do programa Excel.

Foi realizada a análise exploratória dos dados para avaliar a distribuição e características das variáveis, identificar a ocorrência de dados perdidos, inconsistência nos dados e/ou dos registros, além de conhecer a distribuição das variáveis da estimativa da associação entre potenciais variáveis independentes e as variáveis respostas.

A análise estatística foi realizada baseando-se nos testes qui-quadrado e exato de Fisher para avaliar a associação entre as variáveis, com nível de significância de 5\%. As análises foram realizadas no pacote estatístico Stata12.

Foram elaboradas propostas compartilhadas com a VIEP, para contribuir com o planejamento da gestão pública em relação as medidas de controle e prevenção da esquistossomose na região.

\section{RESULTADOS E DISCUSSÃO}

No Brasil a estimativa da prevalência da esquistossomose é de 5,4\% [11], sendo considerado um dos países de maior distribuição da doença devido a quantidade de casos e a gravidade [12], com milhões de indivíduos vivendo em áreas de contaminação, principalmente nas regiões Nordeste e Sudeste do país, com destaque à Bahia que é um estado endêmico para a doença [11].

No Oeste da Bahia alguns municípios apresentam quantidades expressivas de contaminação, porém a região apresenta em média uma baixa prevalência de casos [13]. A prevalência de casos encontrada no município de Barreiras em nosso estudo manteve-se abaixo de 1\% (tabela 1), corroborando com a literatura. Mesmo com baixa prevalência da doença, Barreiras é o município com maior número de casos da região Oeste, segundo os prontuários disponibilizados pela Vigilância Epidemiológica. Não há trabalhos sobre essa parasitose no município, visto que é uma doença negligenciada pelo serviço de saúde.

Tabela 1. Prevalência de casos de esquistossomose em moradores no município de Barreiras no período de 2015-2018.

\begin{tabular}{l|l|l}
\hline Ano & Número de casos & Prevalência \\
\hline 2015 & 42 & $0,027 \%$ \\
2016 & 23 & $0,014 \%$ \\
2017 & 15 & $0,009 \%$ \\
2018 & 18 & $0,011 \%$ \\
\hline
\end{tabular}

Os fatores socioambientais influenciam diretamente a prevalência da esquistossomose, como observado em nossa investigação. Dentre os bairros da residência dos participantes da pesquisa, houve maior frequência de moradores da zona rural (13.54\%), seguido pelos bairros Santa Luzia (11,46\%), Jardim Ouro Branco (8,33\%), Morada da Lua e Centro, ambos com $4,17 \%$.

Essa predominância de parasitados moradores em áreas rurais pode ser esclarecida pelo fato de que essas pessoas apresentam acesso limitado ao serviço público de saúde devido à distância de suas moradias e aos transportes precários 
dessas regiões [6]. Nessas áreas os moradores ficam mais expostos à contaminação por se encontrarem em constante contato com rios e lagoas, e podem ter contato com o caramujo contaminado pelo helminto [14].

Em relação aos bairros de moradia dos parasitados no município, a frequência de casos pode ser explicada pelo fato das ruas de Barreiras não possuírem bueiros ou estarem danificados, fazendo com que em períodos de chuva as ruas fiquem alagadas. Esse fator pode proporcionar a reprodução do caramujo e, consequentemente, o desenvolvimento do parasito, contaminando moradores desses bairros urbanos [15].

A análise do provável bairro da infecção apontou que a maioria dos casos, correspondente a $52,94 \%$, ocorreram em zona rural, de onde podemos relacionar diretamente à presença de fatores socioambientais, como condições precárias de saneamento básico que favorecem o desenvolvimento de parasitoses de circulação hídrica, corroborando com a literatura científica [16]. Estudos realizados em Vaquejada, Passagem do Engenho e Cristópolis, cidades do Oeste baiano, apontaram que nos anos de 2006 e 2007 houve um aumento nos casos de contaminação ligado à falta de educação sanitária e a falta de tratamento dos casos já existentes [13].

No município de Catolândia, situado também no Oeste baiano, no período de 40 anos, houve uma redução dos casos de contaminação, porém o município apresenta coleções hídricas por todo seu território que abrigam moluscos do gênero Biomphalaria, possibilitando contaminações e reinfecções na população [17].

Ao analisarmos o fator ambiental coleção hídrica, observou-se que os Rio Grande e Ribeirão foram os que mais tiveram casos de infecção, ambos correspondentes a $14,71 \%$ dos casos, seguido pelo Rio Canal, correspondendo a 11,76\% dos casos de infecção.

As coleções hídricas apresentam influência significativa na ocorrência de esquistossomose [18]. No município de Barreiras essas coleções são utilizadas constantemente por moradores em atividades profissionais, domésticas e lazer. Bairros do município, principalmente em zonas rurais, devido à falta de saneamento básico, a ocorrência de esgoto a céu aberto é frequente, o que leva a contaminação dos mananciais aquáticos na região. No bairro de Cascalheiras, em outro estudo realizado no município de Barreiras, constatouse que a falta de coleta de lixo, esgoto a céu aberto e ausência de sanitários em algumas residências favoreciam os casos de infeções por parasitoses nos moradores [16].

Nossos resultados apontaram diferença significativa na relação entre a idade do paciente e a forma clínica da doença (pvalor $=0,03$ ), conforme a figura 1 . Observamos que crianças e adultos apresentam maior probabilidade de desenvolverem a forma intestinal da doença, possivelmente pelo fato de serem a faixa etária em que os banhos de rio são mais frequentes, enquanto que em idosos por estarem mais tempo expostos à contaminação possuem maior probabilidade de desenvolverem a forma hepatoesplênica, que é a forma mais grave da doença. Evidenciando que os fatores sociais como estilo de vida influenciam a contaminação pelas cercárias do Schistossoma mansoni.

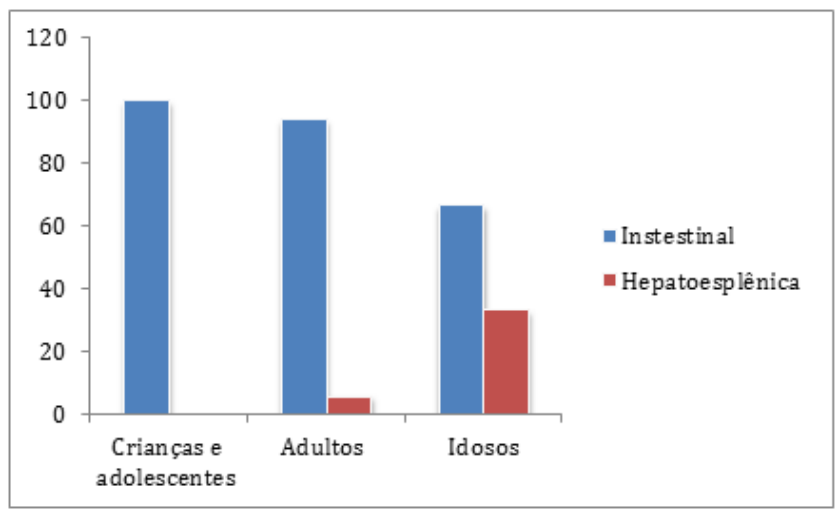

Figura 1. Gráfico de associação entre as variáveis forma clínica e idade nos casos de esquistossomose em moradores no município de Barreiras no período de 2015-2018

\section{CONCLUSÃO}

Fica evidente que os fatores sociais definidos pela Organização Mundial de Saúde (OMS) como aqueles relacionados as condições em que uma pessoa vive e trabalha, influenciam a contaminação e desenvolvimento da esquistossomose. Destacando-se também o papel dos fatores ambientais como mantenedores do ciclo biológico das parasitoses em geral, incluindo a esquistossomose. A ausência de saneamento básico e de infraestrutura, como escoamento de água no bairro de moradia; presença de acúmulo de água nas ruas; presença de coleção hídrica próxima à moradia; uso de águas de rios, córregos ou represas para banho, recreação ou uso doméstico são fatores de risco importantes para a contaminação nesta parasitose.

Nossos resultados nos levam a refletir que são necessárias tomadas de decisões pelo poder público no que tange o planejamento das estratégias de prevenção e controle da esquistossomose, com mais investimento em infraestrutura das áreas urbanas e rurais, saneamento básico, educação em saúde e investimento em campanhas de conscientização da população, minimizando a possibilidade de contaminação e desenvolvimento de esquistossomose.

\section{Referências}

[1] ZONI, Ana Clara; CATALÁ, Laura; AULT, Steven K.. Schistosomiasis Prevalence and Intensity of Infection in Latin America and the Caribbean Countries, 1942-2014: a systematic review in the context of a regional elimination goal. Plos Neglected Tropical Diseases, [S.L.], v. 10, n.3, p. 0004493, 23 mar. 2016.

[2] VERONESI, R.; FOCACCIA, R. Tratado de infectologia. $5^{\mathrm{a}}$ Ed. Atheneu, 2015. ISBN 78-85-388-0648-6. Número de Chamada:616. 9 T776 5ed.rev.a.

[3] ZANARDI, Vanessa Sousa. Prevalência de Infecção de Biomphalaria glabrata infectados por Schistosoma mansoni em Coleções Hídricas de Salvador, Bahia, Brasil. 78 f. il. Dissertação (Mestrado em Patologia) Universidade Federal da Bahia. Fundação Oswaldo Cruz, Instituto Gonçalo Moniz, Salvador; 2018.

[4] ROLLEMBERG, Carla Virginia Vieira. Aspectos Epidemiológicos da Esquistossomose e Co-infecção por enteroparasitas utilizando geoprocessa- 
mento. 2011. 157 f. Dissertação (Mestrado) - Programa de Pós Graduação em Ciências da Saúde, Universidade Federal de Sergipe, Aracaju, 2011.

[5] SECRETÁRIA DE SAÚDE DO ESTADO DA BAHIA. NO08/2017 GT PCE/DIVEP/LACEN/ SUVISA/SESAB: BOLETIM EPIDEMIOLÓGICO DA ESQUISTOSSOMOSE - BAHIA. 01 ed. Salvador: SuvisaDivep, 2017. 2 p.

[6] VIDAL, L. M.; BARBOSA, A. S. et al. Considerações sobre esquistossomose mansônica no município de Jequié, Bahia. Revista de Patologia Tropical, v. 40, n. 4, p. 367-382, 2011.

[7] Instituto Brasileiro de Geografia e Estatistica (IBGE). Estimativas da população. 2018. Disponível em: <https://www.ibge.gov.br/estatisticas-novoportal/sociais/populacao/103estimativas-de-populacao.html?=t=resultados $>$. Acesso: 13/02/2019.

[8] FLORES, P. M. et al. Análise multitemporal da expansão agrícola no município de Barreiras - Bahia (1988 - 2008). Revista de geografia agrária, v. 7, n. 14, p. 1-19, 2012.

[9] KLINK, C. A.; MACHADO, R. D. A conservação do Cerrado brasileiro. Megadiversidade, v. 1, n. 1, p. 147-155, 2005.

[10] PINTO, J. M.; SILVA, C. L. da; OLIVEIRA, C. A. da S. Influência de variáveis climáticas e hidráulicas no desempenho da irrigação de um pivô central no oeste baiano. Eng. Agríc., v.26, n.1, p.76-85, 2006.

[11] ALVES, N. M. F. Prevalência da esquistossomose mansônica em indivíduos do município de Ceará- Mirim no período de 2008 a 2017. Monografia (Bacharel em Biomedicina), 2018. Centro de Biociências, Universidade Federal do Rio Grande do Norte, Natal, RN.

[12] GONÇALVES, A. M. Prevalência de esquistossomose em indivíduos do município de Itaobim no período de 2010 a 2013. 2013. Monografia - Especialização em atenção básica em saúde da família, Universidade Federal de Minas Gerais, Araçuaí, MG.

[13] JOIA, L. C. et al. Referência de esquistossomose entre moradores em um município do interior da Bahia. Rev. APS, v. 13, n. 2, p. 210-216, 2010.

[14] VITORINO, R. R.; SOUZA, F. P. C.; COSTA, A. P. et al. Esquistossomose mansônica: diagnóstico, tratamento, epidemiologia, profilaxia e controle. Rev Bras Clin Med, v. 10, n. 1, p. 39-45, 2012.

[15] SILVA, F. S.; CARVALHO, J. L. V. Efeitos das precipitações ocorridas em janeiro de 2016 no município de Barreiras - Ba. IV Congresso Baiano de Engenharia Sanitária e Ambiental. 2016.

[16] FERREIRA, V. S. et al. Estudo comparativo das enteroparasitoses ocorrentes em duas áreas de Barreiras, Bahia. Natureza on line, v. 11, n. 2, p. 90-95, 2013.

[17] TAVARES-NETO, J. A evolução da esquistossomose mansônica, nos últimos 40 anos, na população de Catolândia, Bahia (Brasil). 2016. Tese Faculdade de Medicina da Bahia, Universidade Federal da Bahia, Salvador, BA.

[18] ALENCAR, M. B. et al. Esquistossomose mansônica: uma análise de indicadores epidemiológicos no estado de Alagoas entre os anos de 2013 e 2015. Diversitas Journal, v. 1, n. 3, p. 266-274, 2016.

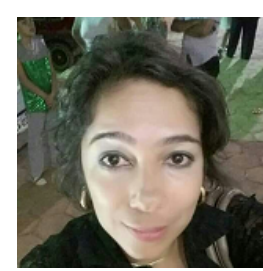

\section{DAYANE OTERO RODRIGUES}

Prof $^{a}$ Adjunta C I da Universidade Federal do Oeste da Bahia (UFOB), Coordenadora do Comitê de Ética em Pesquisa da UFOB, Doutora em Imunologia e Parasitologia aplicadas, Universidade Federal de Uberlândia (UFU - 2010), com tese desenvolvida em Microbiologia Hospitalar, Mestre em Imunologia e Parasitologia aplicadas (UFU - 2003), Bacharel e licenciada em Ciências Biológicas (UFU - 2000), Técnica em Patologia Clínica - Escola Técnica de Saúde (ESTES - UFU - 1999). Tem experiência em Microbiologia e Parasitologia, com ênfase em bacteriologia hospitalar, epidemiologia clássica de infecções hospitalares e de enteroparasitoses.

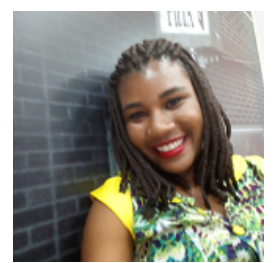

LARISSA HELLEN DOS SANTOS PEREIRA

Bacharel em Ciências Biológicas pela Universidade Federal do Oeste da Bahia. Tem interesse pela área de Zoologia, especialmente por insetos, Parasitologia e Anatomia. 